\title{
A prospective phase I multicentre randomized cross-over pharmacokinetic study to determine the effect of food on abiraterone pharmacokinetics
}

\author{
Floor J. E. Lubberman ${ }^{1} \cdot$ Guillemette E. Benoist ${ }^{1} \cdot$ Winald Gerritsen $^{2} \cdot$ David M. Burger $^{1} \cdot$ Niven Mehra $^{2}$. \\ Paul Hamberg ${ }^{3} \cdot$ Inge van Oort $^{4} \cdot$ Nielka P. van Erp ${ }^{1}$
}

Received: 26 May 2019 / Accepted: 30 August 2019 / Published online: 12 September 2019

(c) The Author(s) 2019

\begin{abstract}
Purpose Abiraterone acetate is used at a fixed oral dose of $1000 \mathrm{mg}$ once daily (OD) taken fasted. By administering abiraterone acetate with food, a reduced dose can potentially be given while maintaining equivalent abiraterone exposure. Moreover, administering abiraterone acetate with a breakfast is considered more patient friendly. The aim of this study was to establish the bio-equivalent lower dose of abiraterone when taken with a continental breakfast (CB) compared to the standard intake of $1000 \mathrm{mg}$ OD fasted.

Methods In this phase I, randomized cross-over, multi-center study, abiraterone pharmacokinetics (PK) were evaluated in patients with metastatic castration-resistant prostate cancer who were treated for 14 days with $1000 \mathrm{mg}$ abiraterone acetate taken fasted, followed by 14 days of treatment with $500 \mathrm{mg}$ taken with a CB.

Results 14 patients were enrolled into the study, of whom 12 were eligible for PK analysis. The geometric mean ratio (GMR) (fed/fasted) was 0.88 (90\% CI 0.73-1.07) for area-under-the-curve $\left(\mathrm{AUC}_{0-24 \mathrm{~h}}\right), 1.03$ (90\% CI 0.79-1.34) for $C_{\max }$ and 0.81 (90\% CI 0.60-1.10) for $C_{\text {trough }}$, respectively. High inter-patient variability ( $>50 \%$ ) was found for all PK parameters under both intake conditions. Patients seemed to be slightly more satisfied about the intake of $500 \mathrm{mg}$ abiraterone acetate when taken with a CB compared to $1000 \mathrm{mg}$ fasted.

Conclusion In conclusion, a bioequivalent lower dose of abiraterone taken with food could not be established in our study. Although based on the absence of a exposure-toxicity relationship, the strict bioequivalence margins as defined by the FDA guidelines could be applied more flexible for abiraterone. Information on the effect of food on abiraterone pharmacokinetics as presented in our study can be used for patients with difficulties taken their medication fasted.
\end{abstract}

Keywords Abiraterone $\cdot$ Bioequivalence $\cdot$ Pharmacokinetics $\cdot$ Food $\cdot$ Prostate cancer

Floor J. E. Lubberman and Guillemette E. Benoist contributed equally.

Electronic supplementary material The online version of this article (https://doi.org/10.1007/s00280-019-03952-w) contains supplementary material, which is available to authorized users.

Nielka P. van Erp

nielka.vanerp@radboudumc.nl

1 Department of Pharmacy (864), Radboud Institute for Health Sciences, Radboud University Medical Center, PO Box 9101, 6500 HB Nijmegen, The Netherlands

2 Department of Medical Oncology, Radboud Institute for Health Sciences, Radboud University Medical Center, Geert Grooteplein Zuid 10, 6525 GA Nijmegen, The Netherlands

\section{Introduction}

With the introduction of oral targeted anti-cancer drugs, the intake of food as a cause of intra-patient variability in drug absorption has become relevant. As part of the registration

3 Department of Medical Oncology, Franciscus Gasthuis and Vlietland, Kleiweg 500, 3045 PM Rotterdam, The Netherlands

4 Department of Urology, Radboud Institute for Health Sciences, Radboud University Medical Center, Geert Grooteplein Zuid 10, 6525 GA Nijmegen, The Netherlands 
process of these new drugs, studies to quantify the effect of food on pharmacokinetics are routinely performed. When food affects drug absorption, the advised intake regime is often fasted for oncologists [1].

One of the drugs with an outspoken food effect is abiraterone acetate (AA) $\left(\right.$ Zytiga $\left.^{\circledR}\right)$. AA is a pro-drug of abiraterone. Abiraterone is a selective inhibitor of cytochrome (CYP) 17A1, a crucial enzyme in androgen biosynthesis, resulting in virtually undetectable serum and intra-tumor androgen levels and thereby resulting in antitumor activity in patients with locally advanced or metastatic prostate cancer (mHSPC and mCRPC) [2-4]. AA tablets are administered at a fixed oral dose of $1000 \mathrm{mg}$ OD in a fasted state in combination with $10 \mathrm{mg}$ prednis(ol)one daily [5].

Abiraterone acetate was developed to overcome the poor bioavailability of the initially formulated abiraterone. Nevertheless, also AA shows very limited bioavailability mainly due to its physiochemical properties of low solubility in aqueous media and low permeability properties [6]. The bioavailability of AA is majorly affected by ingestion with food. However, large differences in the influence of food on pharmacokinetics of AA are seen between different studies. Chi et al. showed that the intake of AA $1000 \mathrm{mg}$ with a lowfat FDA meal in healthy volunteers resulted in a sevenfold increase in $C_{\max }$ and a fivefold increase in $\mathrm{AUC}_{0-\infty}$ compared to fasted intake. Whereas, with a high-fat FDA meal a 17-fold increase in $C_{\max }$ and a tenfold increase in $\mathrm{AUC}_{0-\infty}$ was seen [7]. Surprisingly, a more modest difference was seen when mCRPC patients ingested $1000 \mathrm{mg} \mathrm{AA}$ with a low-fat FDA meal compared to modified fasted intake. The geometric mean ratios (GMRs) fed versus fasted were only 1.35 for $C_{\max }$ and 1.07 for $\mathrm{AUC}_{0-24 \mathrm{~h}}$ [7]. In another study by Attard et al., AA capsules administered with high-fat food in mCRPC patients resulted in a 4.4-fold increased AUC $0-\infty$ [8]. Despite these large differences, the overall picture suggests that AA is much better absorbed in the presence of food. This effect is most likely due to the better solubility of AA in the presence of food, of which the amount of fat in the meal is thought to be the most important [7]. The clinical potential of food to reduce the required dose of AA was shown by Szmulewitz et al. They showed that a reduced dose of $250 \mathrm{mg}$ AA taken with a low-fat breakfast was noninferior compared to the standard dose of $1000 \mathrm{mg}$ taken fasted for the surrogate endpoint ( $>50 \%$ PSA response) [9].

Since the effect of food on abiraterone PK is not fully established, a bioequivalence study comparing fasted versus fed intake could contribute to the understanding the effect of food on abiraterone pharmacokinetics. In addition, ingestion of drugs with a breakfast is easier to implement in the patient's daily life and preferred by most [10]. Consequently, patients are less likely to forget their medication and therefore, an intake regimen with food might positively affect drug adherence.
Therefore, in this study, we aimed to determine the effect of a continental breakfast (CB) on abiraterone exposure and establish the dose reduction required to reach a bio-equivalent exposure compared to the registered intake of $1000 \mathrm{mg}$ OD without food.

\section{Methods}

\section{Study design and participants}

For this multicentre, phase 1, cross-over study, we enrolled patients from two investigational sites in the Netherlands (Franciscus Gasthuis and Vlietland and Radboud university medical center). Eligible patients were aged 18 or older, had metastatic castration-resistant prostate cancer, were treated with $1000 \mathrm{mg}$ abiraterone acetate $\left(\mathrm{Zytiga}^{\circledR}\right)$ OD fasted (both patients on treatment and patients who started treatment were eligible) and had an Eastern Cooperative Oncology Group (ECOG) performance status of 0-2 [5]. Patients with gastrointestinal abnormalities that could influence the absorption of AA were excluded. The use of other substances known or likely to interfere with the pharmacokinetics of abiraterone was prohibited during this study.

The trial was approved by the Investigational Review Board of Radboud university medical center, Nijmegen, the Netherlands. The trial was conducted in accordance with Good Clinical Practice and the Declaration of Helsinki and registered at ClinicalTrials.gov, number NCT02883166. All patients gave written informed consent before entering the study.

\section{Procedures}

Since the effect of a $\mathrm{CB}$ on abiraterone exposure was uncertain and the study was conducted in patients with cancer, a lead-in phase of three patients was introduced. Based on the data of Chi et al., at least a twofold increase in abiraterone exposure taken with food was presumed [7]. Therefore, patients received $500 \mathrm{mg}$ AA with CB. Pharmacokinetic (PK) evaluation after 2 weeks was conducted to prevent unnecessary over- or under-dosing. During the first 2 weeks, patients took $1000 \mathrm{mg}$ AA OD in a fasted state at 08:00 am followed by one of the standardized CBs (Table 1) at 09:00 am. After reaching steady-state pharmacokinetics (day 14), blood was collected in K2-EDTA tubes at $t=0,1,2,3,4,5,6,8,10,12$ and $24 \mathrm{~h}$ after AA intake for PK assessment. Subsequently, these patients switched to $500 \mathrm{mg}$ AA OD (50\% dose reduction) in combination with a standardized CB at 08:00 am. At day 28 of the study, after reaching steady-state pharmacokinetics, the second PK assessment was performed. The results of the first 3 patients were analyzed and evaluated before 
Table 1 Breakfast composition

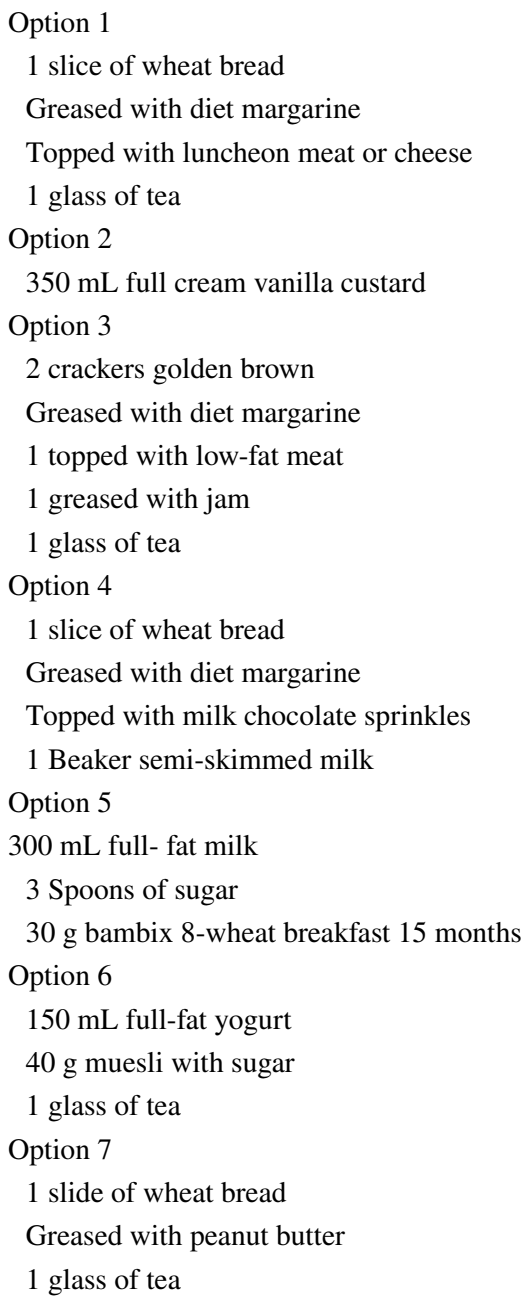

All breakfasts contain the same amount of fat namely $9-10 \mathrm{~g}$

continuation. If the GMR of the $\mathrm{AUC}_{0-24 \mathrm{~h}}$ and $C_{\max }$ of the reduced dose taken with food compared to the $1000 \mathrm{mg}$ fasted appeared to be within the threshold for bioequivalence (0.8-1.25), the next 21 patients would be exposed to the $50 \%$ dose reduction with food. When the $50 \%$ dose reducing strategy in the lead-in phase led to a ratio of AUC 0-24h and $C_{\max }$ of more than 1.25 , a $75 \%$ dose reduction (i.e., $250 \mathrm{mg}$ ) would be tested for bioequivalence in a next lead-in of 3 new patients (Fig. 1).

After each treatment period, patients were asked to complete the validated cancer therapy satisfaction questionnaire (CTSQ) [11]. In the CTSQ, patients are asked about their feelings about side effects, satisfaction with therapy and their expectations of therapy. A difference of $\geq 8.3$ points in patients expectations of therapy (ET), $\geq 5.9$ point in patients satisfaction with therapy (SWT) and $\geq 10.3$ for patients feelings about side effect (FSE) were considered clinically relevant [12].
The CBs were composed by a dietician from Radboudumc and designed to be similar to the breakfasts our patients normally would have. All proposed breakfasts contained the same amount of fat $(9-10 \mathrm{~g}, 25-50 \%$ of total caloric intake). The total amount of calories, proteins and carbohydrates differed per breakfast, ranging, respectively, 160-320 Cal, 5-11 $\mathrm{g}$ and 15-50 g (Table 1). The choice of $\mathrm{CB}$ was at patients' discretion.

Blood samples for measurement of abiraterone PK were collected on ice and centrifuged within $1 \mathrm{~h}$ at $1900 \mathrm{~g}$ for at least $5 \mathrm{~min}\left(4^{\circ} \mathrm{C}\right)$. Plasma samples were stored at $-40{ }^{\circ} \mathrm{C}$ until the day of analysis. Abiraterone plasma concentrations were measured using a validated liquid chromatography tandem mass spectrometry method with a range of $1-500 \mathrm{mg} / \mathrm{L}$ [13].

\section{Outcomes}

The primary endpoint of this study was to determine the equivalent reduced dose of $\mathrm{AA}$ when taken with a $\mathrm{CB}$ compared to the recommended intake of AA $1000 \mathrm{mg}$ OD taken fasted. Bioequivalence is assumed when the geometric mean ratio (GMR) including the $90 \% \mathrm{CI}$ of the $\mathrm{AUC}_{0-24 \mathrm{~h}}, C_{\max }$ and $C_{\text {trough }}$ is within the thresholds of 0.80 and 1.25. Due to the mild toxicity profile of abiraterone (e.g., no treatment-related grade 3 or 4 toxicities occurred at doses twice the registered dose), CI crossing the upper limit of 1.25 is accepted [8].

\section{Statistical analysis}

Based on an intra-patient coefficient of variation (CV) of $25 \%$, and a reference ratio of 1.0 , a sample size of 24 patients was required for a power of $80 \%$, a two-side significance level of 0.05 and a CV of $20 \%$ on the log-transformed data [14]. The $\mathrm{AUC}_{0-24 \mathrm{~h}}, C_{\text {max }}, C_{\text {trough }}$, were calculated using noncompartmental analyses in WinNonlin/Phoenix version 6.3 (Pharsight Corporation ${ }^{\circledR}$ ). The CTSQ questionnaires were scored following the guideline provided by Abetz et al. [12]. The differences in CTSQ scores were analyzed according to Altman et al. to correct for a possible period effect [15].

\section{Results}

Between November 2016 and January 2019, a total of 14 Caucasian patients treated with AA for metastatic castration-resistant prostate cancer were enrolled in the study, of which 12 were evaluable for pharmacokinetic analysis. One patient stopped AA therapy before the second PK evaluation due to elevation in liver enzymes and one patient did not take the medication as prescribed. Both patients were, therefore, excluded from analysis. Of the 12 eligible patients, 10 received prior systemic treatment. Two patients were 


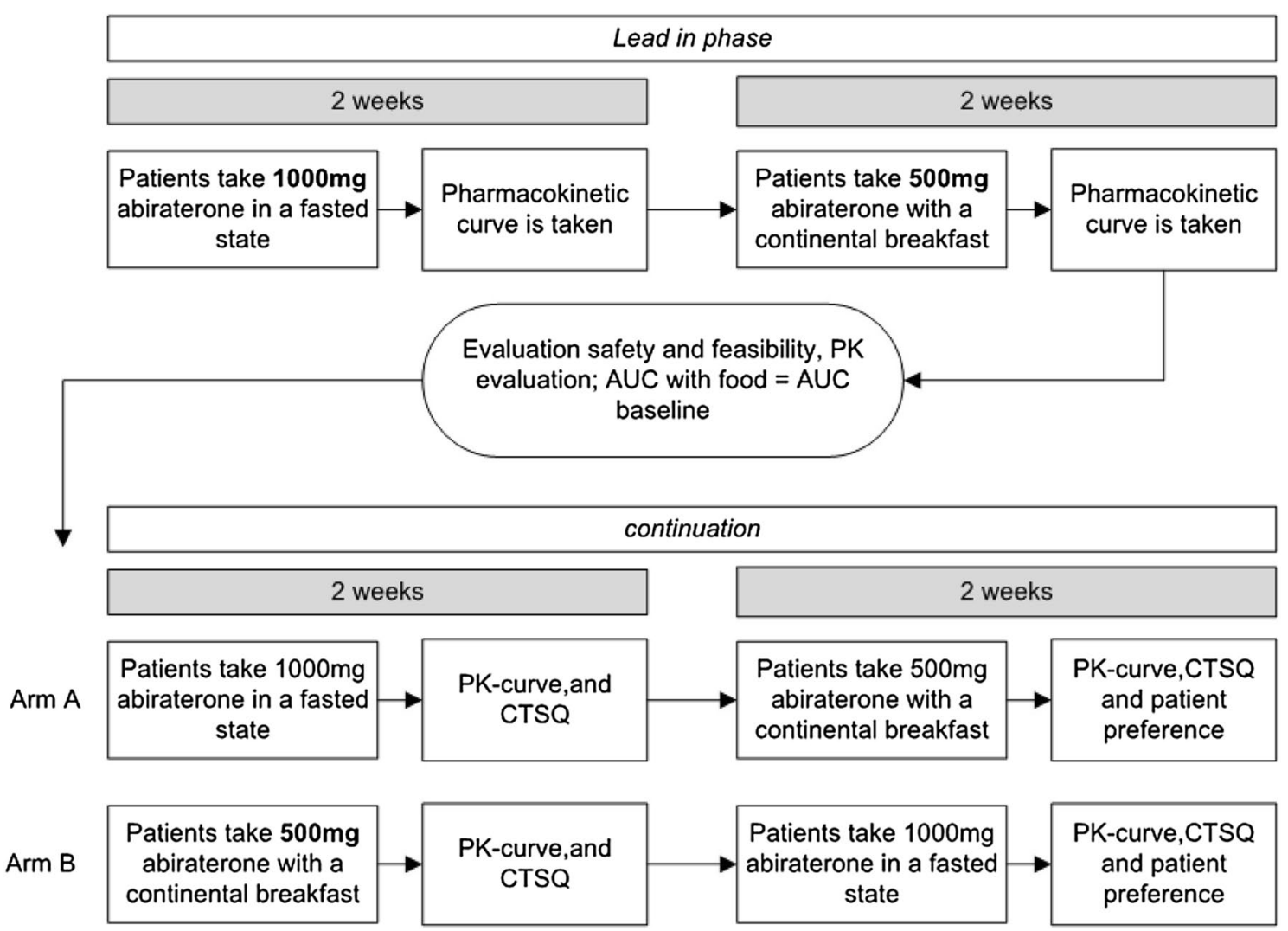

Fig. 1 Study design

treatment naïve. Eight patients already used AA before study participation. The median age of the patients was 70 (range 64-93) years (Table 2).

In the initial lead-in phase of the study, three patients were treated with a reduced dose of $500 \mathrm{mg}$ OD with a $\mathrm{CB}$. These three patients showed a geometric mean (GM) $\mathrm{AUC}_{0-24 \mathrm{~h}}$ value with and without food of $595 \mathrm{mg} \mathrm{h} / \mathrm{L}$ and $598 \mathrm{mg} \mathrm{h} / \mathrm{L}$, respectively. The GM $C_{\max }$ values with and without food were $116 \mathrm{mg} / \mathrm{L}$ and $115 \mathrm{mg} / \mathrm{L}$, respectively. The GMRs fed/fasted calculated in these patients were 1.01 and 0.99 for $\mathrm{AUC}_{0-24 \mathrm{~h}}$ and $C_{\max }$. Based on these results, a reduced dose of $50 \%$ with a $\mathrm{CB}$ was studied in the following patients.

In the final $\mathrm{PK}$ analysis in 12 patients, the $\mathrm{GM}$ of the AUC $_{0-24 \mathrm{~h}}$ was $776 \mathrm{mg} \mathrm{h} / \mathrm{L}$ and the $C_{\text {max }}$ was $148 \mathrm{mg} / \mathrm{L}$, respectively, when $1000 \mathrm{mg}$ abiraterone was taken in a fasted state. When a reduced dose of $500 \mathrm{mg}$ abiraterone was taken with a $\mathrm{CB}$, the $\mathrm{GM}$ of the $\mathrm{AUC}_{0-24 \mathrm{~h}}$ and the $C_{\max }$ was $686 \mathrm{mg} \mathrm{h} / \mathrm{L}$ and $152 \mathrm{mg} / \mathrm{L}$, respectively. The GM of the $C_{\text {trough }}$ was $10.7 \mathrm{mg} / \mathrm{L}$, when $1000 \mathrm{mg}$ was taken fasted, compared to $8.7 \mathrm{mg} / \mathrm{L}$, when $500 \mathrm{mg}$ was taken with a CB (Fig. 2, Table 3).

To determine the difference between both intake regimens on $\mathrm{AUC}_{0-24 \mathrm{~h}}, C_{\max }$ and $C_{\text {trough }}$ the GMRs fed/fasted were calculated including the $90 \% \mathrm{CI}$. For $\mathrm{AUC}_{0-24 \mathrm{~h}}$ the
Table 2 Patient characteristics at baseline

\begin{tabular}{lll}
\hline Characteristics & No. & $\%$ \\
\hline $\begin{array}{l}\text { Patients } \\
\text { Age, year }\end{array}$ & 12 & 100 \\
$\quad$ Median (range) & $70(64-93)$ & 100 \\
Ethnics & & \\
$\quad$ Caucasian & 16 & \\
BMI, kg/m ${ }^{2}$ & & 50 \\
$\quad$ Median (range) & $29(21-37)$ & 50 \\
ECOG performance status & & 83 \\
0 & 6 & 17 \\
$\quad 1$ & 6 & \\
Received previous treatment & & \\
Yes & 10 & \\
No & 2 & \\
PSA (ng/mL) & & \\
$\quad$ Median (range) \\
Hemoglobin (mmol/L) \\
$\quad$ Median (range) \\
LDH (ng/mL)
\end{tabular}

ECOG Eastern Cooperative Oncology Group 


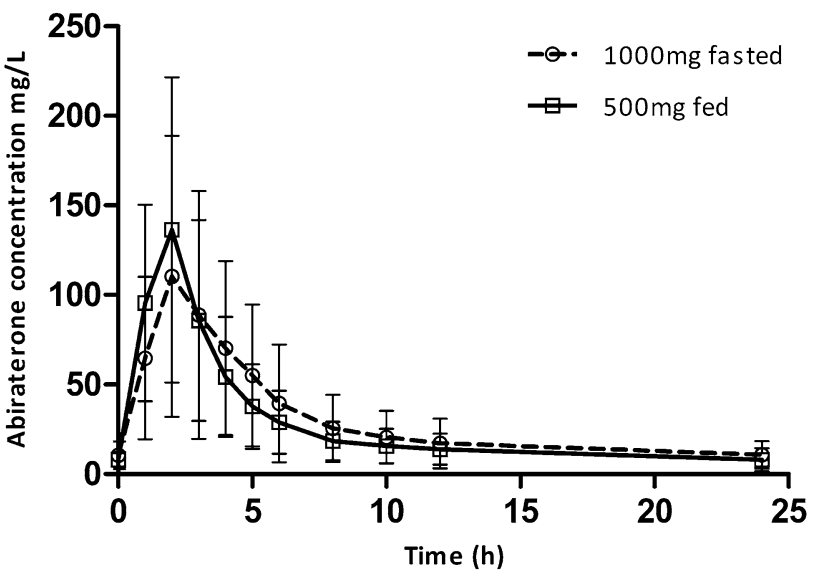

Fig. 2 Concentration time curve of $1000 \mathrm{mg}$ abiraterone acetate taken fasted and $500 \mathrm{mg}$ abiraterone acetate taken with a continental breakfast

Table 3 Pharmacokinetic parameters abiraterone

\begin{tabular}{lcc}
\hline & $1000 \mathrm{mg}$ fasted & $500 \mathrm{mg}$ fed \\
\hline $\mathrm{AUC}_{0-24 \mathrm{~h}}, \mathrm{mg} \mathrm{h} / \mathrm{L}, \mathrm{GM}(90 \mathrm{CI}$, & $776(514-1172)$ & $686(455-1035)$ \\
$\mathrm{CV} \%)$ & & \\
$C_{\text {max }}, \mathrm{mg} / \mathrm{L}, \mathrm{GM}(90 \mathrm{CI}, \mathrm{CV} \%)$ & $148(98-223)$ & $152(99-235)$ \\
$C_{\text {trough }}, \mathrm{mg} / \mathrm{L}, \mathrm{GM}(90 \mathrm{CI}, \mathrm{CV} \%)$ & $10.7(6.6-14.9)$ & $8.7(4.8-12.4)$ \\
\hline
\end{tabular}

$A U C_{0-24 h}$ area under the concentration time curve, $C_{\max }$ maximum observed plasma concentration, $C_{\text {trough }}$ plasma concentration at $t=24 \mathrm{~h}, G M$ geometric mean, $C I$ confidence interval, $C V \%$ percentage of coefficient of variation defined by (standard deviation/ mean) $\times 100$

GMR was 0.88 (90\% CI 0.73-1.07), for $C_{\max }$ the GMR was 1.03 (90\% CI 0.79-1.34) and for $C_{\text {trough }}$ the GMR was 0.81 (90\% CI 0.60-1.10). These GMRs with their 90\% confidence intervals do not fall within the thresholds predefined for bioequivalence (0.80-1.25) (Fig. 3).

Due to the large variation in the individual GMRs observed in our study, we decided after 12 patients that bioequivalence could not be confirmed even when the predefined number of 24 patients would be met. Therefore, further enrolment was stopped.

Inter-patient variability (CV \%) for $\mathrm{AUC}_{0-24 \mathrm{~h}}, C_{\max }$, and $C_{\text {trough }}$ was $65 \%$ vs. $57 \%, 55 \%$ vs. $57 \%$ and $72 \%$ vs. $75 \%$, respectively, when abiraterone was taken fasted compared to fed.

Compared to $1000 \mathrm{mg}$ taken fasted, patients seem to be slightly more positive about the intake of $500 \mathrm{mg}$ abiraterone with a continental breakfast based on the differences in FSE, SWT and ET fasted versus fed of 2.8, 6.6 and 8.5 points, respectively (Table 4).

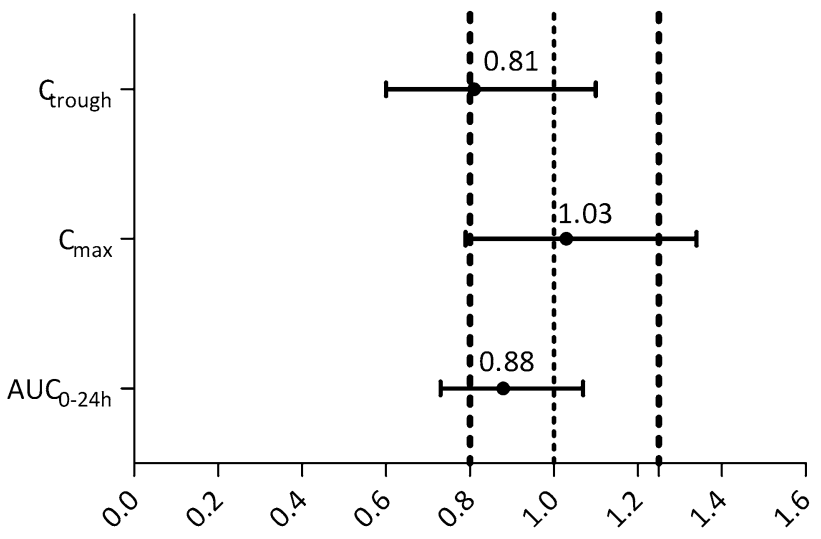

Fig. 3 Geometric mean ratio including their confidence interval. Vertical lines represent the threshold of 0.8 and 1.25 as defined by the FDA

\section{Discussion}

We aimed to establish the dose reduction required to reach a bioequivalent exposure compared to the standard intake of $1000 \mathrm{mg}$ abiraterone acetate OD without food. Although the GMRs of the intake of $500 \mathrm{mg}$ abiraterone acetate with a continental breakfast compared to $1000 \mathrm{mg}$ taken fasted are within the thresholds of 0.80 and 1.25 , the $90 \%$ confidence intervals do not meet the criteria for bioequivalence. However, it is known that no exposure-toxicity relation has been found for abiraterone when investigated up until doses of $2000 \mathrm{mg}$ [8]. Therefore, the strict bio-equivalence margins as defined by the FDA guidelines could be applied more flexible for abiraterone.

To the best of our knowledge, this is the first study to investigate the bioequivalence of an adjusted AA dose when taken with food. Our data demonstrated that a 50\% dose reduction resulted in a GMR for the $\mathrm{AUC}_{0-24 \mathrm{~h}}$ and $C_{\text {trough }}$ below 1.0. Based on our PK data, no further dose reduction was deemed feasible. However, Szmulewitz et al. have shown that a $75 \%$ reduced AA dose taken with a low-fat breakfast resulted in similar PSA response rates compared to the standard fasted intake of AA $1000 \mathrm{mg}$ OD [9]. The descriptive PK data in their study demonstrated that the abiraterone $C_{\text {trough }}$ levels were lower in the group treated at the reduced dose with food compared to the full dose taken fasted [9]. Nevertheless, despite the lower $C_{\text {trough }}$ levels, the percentage of patients reaching an adequate PSA response remained comparable between both intake regimes [9]. The majority of the patients in the study of Szmulewitz et al. was treated prior to receiving chemotherapy and might, therefore, be more sensitive to lower abiraterone concentrations. $\mathrm{Xu}$ et al. showed that the EC50 of the PSA for abiraterone was $1.56 \mathrm{ng} / \mathrm{mL}$ in chemotherapy-naïve patients and $4.75 \mathrm{ng} / \mathrm{mL}$ in patients 
Table 4 CTSQ

\begin{tabular}{lll}
\hline & $1000 \mathrm{mg}$ fasted $(N=\ldots)$ & $500 \mathrm{mg}$ fed $(N=\ldots)$ \\
\hline Expectations of therapy ET, mean $(95 \% \mathrm{CI})(n=11)$ & $38.6(28.2-49.1)$ & $47.1(35.6-58.5)$ \\
Feelings about side effects FSE, mean $(95 \% \mathrm{CI})(n=10)$ & $76.0(65.1-87.0)$ & $78.8(64.0-93.5)$ \\
Satisfaction with therapy SWT, mean $(95 \% \mathrm{CI})(n=10)$ & $81.3(72.5-90.0)$ & $87.9(80.5-95.3)$ \\
\hline
\end{tabular}

$C T S Q$ cancer therapy satisfaction questionnaire, $C I$ confidence interval

who underwent previous chemotherapy [16]. Though, due to the large confidence intervals around the observation of Xu et al., the data of those trials should be interpreted carefully. Our population mainly consisted of patients post chemotherapy, Therefore, exposure levels similar to those reached when $1000 \mathrm{mg} \mathrm{AA}$ taken fasted were aimed for. The results of our study are based on 12 patients instead of the predefined 24 patients. Variation of the individual GMRs of the $\mathrm{AUC}_{0-24 \mathrm{~h}}$ and $C_{\max }$ was larger than expected. Re-estimation of the sample, size based on the larger variability as observed in our study, learned us that bioequivalence could not be demonstrated in the predefined number of 24 patients. Therefore we considered it unethical to further conduct the study. Nevertheless, as 12 patients are the minimal number necessary for a bioequivalence study as stated by the FDA, the PK results from our study are still of value for further interpretation [17]. Since we could not demonstrate bioequivalence, the switch of large groups of patients to an alternative intake regime of $500 \mathrm{mg}$ taken with food cannot be supported. However, because the GMRs of the $\mathrm{AUC}_{0-24 \mathrm{~h}}, C_{\max }$ and $C_{\text {trough }}$ were within the threshold of $0.8-1.25$, the data are suggestive for bioequivalence [18]. Therefore, in individual patients, intake of $500 \mathrm{mg}$ with a CB accompanied with PK monitoring could be considered when experiencing difficulties with a fasted intake.

During our study, patients could choose between seven different types of breakfast. Though standardized for the amount of fat, differences in total caloric intake between the breakfasts were present. This could have enhanced the interpatient variability. However, our results demonstrate that the inter-patient variability in our study was comparable to other data and was not increased when AA was ingested with food $[16,19]$. It, therefore. is not expected that the differences in breakfast contribute to the inter-patient variability.

Our study is the first to explore patient satisfaction when abiraterone is taken with food as a clinical outcome. Our study indicates a modest improvement in treatment satisfaction and expectation of therapy when $500 \mathrm{mg}$ of abiraterone was taken with food. The absence of any notable differences regarding patients feelings about side effects is likely due to the limited gastro-intestinal adverse events such as diarrhea or nausea that patients experience when treated with abiraterone (1-3\% grade 3 or 4) [3]. Therefore, ingesting
AA with food will not contribute to a reduction of these adverse events.

For several other drugs with this large intra- and interpatient PK variability, the formulation was adjusted to increase drug absorption and drug exposure to achieve a better predictable response in patients. Examples of drugs with alternative formulations due to absorption issues are regorafenib and olaparib $[20,21]$. Also for AA, a new formulation is tested, using a continuous flow precipitation technology. This new formulation shows improved bioavailability, and therefore less PK variability. In addition, food does not play a significant role in the absorption of this new abiraterone formulation [22]. We believe that this new formulation, which is not available yet, could help to overcome the issues of highly variable PK and thereby unpredictable treatment effect for patients.

In conclusion, a bioequivalent lower dose of abiraterone taken with food could not be established in our study. Though, information on the effect of food on abiraterone pharmacokinetics as presented in our study can be used.

Acknowledgements We thank patients and their families, all investigators, research nurses: A. Hofboer, K. Saini and S. Ras, dietician: Heidi Zweers who designed the breakfasts used in the study; and 'Betaalbaar Beter' for the financial support.

Funding This study was supported by the health insurance company VGZ within the program 'Betaalbaar Beter'.

\section{Compliance with ethical standards}

Conflict of interest NvE received grants from Novartis, Astellas, AstraZeneca, Bristol-Meyers Squibb, Gilead, Ipsen, Janssen, Pfizer and Roche. IvO received grants from Astellas, Janssen, Sanofi, Beyer and Roche. The other authors declare to have no conflicts of interest.

Open Access This article is distributed under the terms of the Creative Commons Attribution 4.0 International License (http://creativeco mmons.org/licenses/by/4.0/), which permits unrestricted use, distribution, and reproduction in any medium, provided you give appropriate credit to the original author(s) and the source, provide a link to the Creative Commons license, and indicate if changes were made. 


\section{References}

1. Kang SP, Ratain MJ (2010) Inconsistent labeling of food effect for oral agents across therapeutic areas: differences between oncology and non-oncology products. Clin Cancer Res 16(17):4446-4451

2. James ND, de Bono JS, Spears MR, Clarke NW, Mason MD, Dearnaley DP, Ritchie AWS, Amos CL, Gilson C, Jones RJ, Matheson D, Millman R, Attard G, Chowdhury S, Cross WR, Gillessen S, Parker CC, Russell JM, Berthold DR, Brawley C, Adab F, Aung S, Birtle AJ, Bowen J, Brock S, Chakraborti P, Ferguson C, Gale J, Gray E, Hingorani M, Hoskin PJ, Lester JF, Malik ZI, McKinna F, McPhail N, Money-Kyrle J, O'Sullivan J, Parikh O, Protheroe A, Robinson A, Srihari NN, Thomas C, Wagstaff J, Wylie J, Zarkar A, Parmar MKB, Sydes MR, Investigators S (2017) Abiraterone for prostate cancer not previously treated with hormone therapy. N Engl J Med 377:338-351

3. Fizazi K, Scher HI, Molina A, Logothetis CJ, Chi KN, Jones RJ, Staffurth JN, North S, Vogelzang NJ, Saad F, Mainwaring P, Harland S, Goodman OB Jr, Sternberg CN, Li JH, Kheoh T, Haqq CM, de Bono JS, Investigators C-A (2012) Abiraterone acetate for treatment of metastatic castration-resistant prostate cancer: final overall survival analysis of the COU-AA-301 randomised, double-blind, placebo-controlled phase 3 study. Lancet Oncol 13(10):983-992

4. Fizazi K, Tran N, Fein L, Matsubara N, Rodriguez-Antolin A, Alekseev BY, Ozguroglu M, Ye D, Feyerabend S, Protheroe A, Sulur G, Luna Y, Li S, Mundle S, Chi KN (2019) Abiraterone acetate plus prednisone in patients with newly diagnosed high-risk metastatic castration-sensitive prostate cancer (LATITUDE): final overall survival analysis of a randomised, double-blind, phase 3 trial. Lancet Oncol 20(5):686-700

5. FDA Abiraterone (Zytigat) product label. http://www.accessdata .fda.gov/drugsatfda_docs/label/2011/202379lbl.pdf. Accessed 20 Sept 2016

6. FDA (2010) Abirateron (Zytiga) Clinical Pharmacology and Biopharmaceutics review. http://www.accessdata.fda.gov/drugsatfda _docs/nda/2011/2023790rig1s000TOC.cfm. Accessed 21 Mar 2016

7. Chi KN, Spratlin J, Kollmannsberger C, North S, Pankras C, Gonzalez M, Bernard A, Stieltjes H, Peng L, Jiao J, Acharya M, Kheoh T, Griffin TW, Yu MK, Chien C, Tran NP (2015) Food effects on abiraterone pharmacokinetics in healthy subjects and patients with metastatic castration-resistant prostate cancer. J Clin Pharmacol 55(12):1406-1414

8. Attard G, Reid AH, Yap TA, Raynaud F, Dowsett M, Settatree S, Barrett M, Parker C, Martins V, Folkerd E, Clark J, Cooper CS, Kaye SB, Dearnaley D, Lee G, de Bono JS (2008) Phase I clinical trial of a selective inhibitor of CYP17, abiraterone acetate, confirms that castration-resistant prostate cancer commonly remains hormone driven. J Clin Oncol 26(28):4563-4571

9. Szmulewitz RZ, Peer CJ, Ibraheem A, Martinez E, Kozloff MF, Carthon B, Harvey RD, Fishkin P, Yong WP, Chiong E, Nabhan C, Karrison T, Figg WD, Stadler WM, Ratain MJ (2018) Prospective international randomized phase II study of low-dose abiraterone with food versus standard dose abiraterone in castrationresistant prostate cancer. J Clin Oncol 36:1389-1395

10. Lubberman F (2019) A reduced pazopanib dose with food: is it more patient-friendly and does it reduce drug costs? J Clin Oncol 37(suppl):abstr 4564
11. Trask PC, Tellefsen C, Espindle D, Getter C, Hsu MA (2008) Psychometric validation of the cancer therapy satisfaction questionnaire. Value Health 11(4):669-679

12. Abetz L, Coombs JH, Keininger DL, Earle CC, Wade C, BuryMaynard D, Copley-Merriman K, Hsu MA (2005) Development of the cancer therapy satisfaction questionnaire: item generation and content validity testing. Value Health 8(Suppl 1):S41-S53

13. Benoist GE, van der Meulen E, Lubberman FJE, Gerritsen WR, Smilde TJ, Schalken JA, Beumer JH, Burger DM, van Erp NP (2017) Analytical challenges in quantifying abiraterone with LC-MS/MS in human plasma. Biomed Chromatogr 31(11):e3986

14. Diletti E, Hauschke D, Steinijans VW (1991) Sample size determination for bioequivalence assessment by means of confidence intervals. Int J Clin Pharmacol Ther Toxicol 29(1):1-8

15. Altman DG (1991) Practical statistics for medical Research, 1st edn. Chapman \& Hall, London

16. Xu XS, Ryan CJ, Stuyckens K, Smith MR, Saad F, Griffin TW, Park YC, Yu MK, De Porre P, Vermeulen A, Poggesi I, Nandy P (2017) Modeling the relationship between exposure to abiraterone and prostate-specific antigen dynamics in patients with metastatic castration-resistant prostate cancer. Clin Pharmacokinet 56(1):55-63

17. FDA (2002) Guidance for industry bioavailability and bioequivalence studies for orally administered drug products-general considerations. http://www.fda.gov/downloads/Drugs/Developmen tApprovalProcess/HowDrugsareDevelopedandApproved/Appro valApplications/AbbreviatedNewDrugApplicationANDAGeneric s/UCM154838.pdf. Accessed 21 Mar 2016

18. Williams RL, Chen ML, Hauck WW (2002) Equivalence approaches. Clin Pharmacol Ther 72(3):229-237

19. Arasaratnam M, Crumbaker M, Bhatnagar A, McKay MJ, Molloy MP, Gurney H (2019) Inter- and intra-patient variability in pharmacokinetics of abiraterone acetate in metastatic prostate cancer. Cancer Chemother Pharmacol 84:139-146

20. FDA Regorafenib clinical pharmacology and biopharmaceutics review. https://www.accessdata.fda.gov/drugsatfda_docs/ nda/2012/203085Orig1s000ClinPharmR.pdf. Accessed 22 Jan 2019

21. Mateo J, Moreno V, Gupta A, Kaye SB, Dean E, Middleton MR, Friedlander M, Gourley C, Plummer R, Rustin G, Sessa C, Leunen K, Ledermann J, Swaisland H, Fielding A, Bannister W, Nicum S, Molife LR (2016) An adaptive study to determine the optimal dose of the tablet formulation of the PARP inhibitor olaparib. Target Oncol 11(3):401-415

22. Solymosi T, Otvos Z, Angi R, Ordasi B, Jordan T, Molnar L, McDermott J, Zann V, Church A, Mair S, Filipcsei G, Heltovics G, Glavinas H (2017) Novel formulation of abiraterone acetate might allow significant dose reduction and eliminates substantial positive food effect. Cancer Chemother Pharmacol 80(4):723-728

Publisher's Note Springer Nature remains neutral with regard to jurisdictional claims in published maps and institutional affiliations. 